\title{
(1) Hunt for the Hidden Trait
}

\section{Vanamala Alwar, Reeti Kavdia, Nandini Singh, Karuna Rameshkumar}

\author{
Department of Clinical Pathology, St. John's Medical College Hospital, Bangalore, India
}

Address for correspondence: Dr. Karuna Rameshkumar, E-mail: karunark@yahoo.com

\begin{abstract}
Objective: To assess the efficacy of a peripheral smear examination as a screening tool for $\beta$-thalassemia trait. Materials and Methods: 17623 Leishman-stained peripheral smears were evaluated during the period from July 2006 to September 2007. The following parameters were studied: hemoglobin, red blood cell count, mean corpuscular volume, mean corpuscular hemoglobin, mean corpuscular hemoglobin concentration and red cell distribution width. All the cases that showed microcytosis, hypochromia, erythrocytosis and absence of anisopoikilocytosis were suspected of having the thalassemia trait (TT), and all these cases were further evaluated with Alkaline Hemoglobin Electrophoresis for confirmation.

Results: Of the 17623 smears examined, 60 cases were considered suspicious of having TT. Alkaline hemoglobin electrophoresis carried out on all these cases revealed an elevated $\mathrm{HbA}_{2}$ (Mean $=7.5 \%$ ). Five cases evaluated were found to have other hemoglobinopathies (1 Sickle cell trait, $3 \mathrm{Hb}-\mathrm{E}, 1$ thalassemia intermedia).

Conclusion: Careful screening of peripheral smear is an invaluable screening tool for thalassemia trait (PPV - 95\%). There must be awareness among the peripheral centers about the importance of peripheral smear screening and the affected persons should be counseled.
\end{abstract}

Keywords: Iron deficiency anemia, peripheral smear, Thalassemia trait

DOI: $10.4103 / 0974-2727.54802$

\section{INTRODUCTION}

O halassemia is considered the most common genetic disorder worldwide ${ }^{[1]}$ supported

by the fact that over 30 million people are carrying the defective gene. ${ }^{[2]} \beta$-thalassemia, results from mutations causing diminished production of mRNA and decreased synthesis of structurally normal globin, is the most common single gene disorder in India. ${ }^{[1]}$

The three $\beta$-thalassemia syndromes described are:

1. Thalassemia major (homozygous gene defect, present with severe anemia classically described by Cooley).

2. Thalassemia intermedia (homozygous gene defect associated with a moderate degree of anemia).

3. Thalassemia minor or thalassemia trait (TT) (heterozygous state with involved individuals being asymptomatic)..$^{[3]}$

Thalassemia constitutes a major cause of public health morbidity and early mortality in patients. Effective population screening for T'T can dramatically decrease the incidence of thalassemia major births. Though quantitative assessment of abnormal hemoglobins by hemoglobin electrophoresis and DNA studies are the gold standard for diagnosis, they are too expensive and hence cannot be used for mass screening purposes. As thalassemia syndromes are invariably associated with microcytosis and hypochromia in the peripheral smear, peripheral smear examination and red cell indices can be used as preliminary indicators of diagnosis. Hence with this background, it was decided to assess the efficacy of peripheral smear examination as a screening tool for $\beta$ TT.

\section{MATERIALS AND METHODS}

During a one-year-period from July 2006 to September 2007, all peripheral smears stained with Leishman stain, which were done as part of investigations, were evaluated. The smears from patients with malignancy were excluded. The demographic details were retrieved from the charts. 
The other parameters studied using automated Sysmex XT1800i were:

1. Hemoglobin, 2. RBC count, 3. Mean corpuscular volume (MCV), 4. Mean corpuscular hemoglobin (MCH), 5. Mean corpuscular hemoglobin concentration (MCHC) and, 6. Red cell distribution width (RDW)

Perl's stain was used to stain the iron stores in bone marrow and was graded from 0 to 6 . Grade 0 was considered as iron deficient, 1-3 as normal and 4-6 as increased iron stores.

All the cases showing a microcytosis and hypochromia on peripheral smear examination were categorized into two groups:

1. Suspected thalassemia trait (TT), 2. Suspected iron deficiency (IDA), which was considered as control group.

On correlation of peripheral smear findings and red cell indices, TT was suspected in cases that showed microcytosis, hypochromia, presence of target cells, erythrocytosis and absence of anisopoikilocytosis [Figure 1]. These cases were further evaluated with alkaline hemoglobin electrophoresis using cellulose acetate agar (Helene electrophoresis) for confirmation.

Iron deficiency was suspected in patients with microcytic hypochromic blood picture associated with anisopoikilocytosis and low RBC counts. Iron deficiency status was confirmed by serum iron studies including serum iron, serum ferritin (decreased) or bone marrow grade 0 iron stores [Figure 2]. Simple descriptive statistics of mean and percentage were used for comparison, and screening test of positive predictive value was used for assessing the efficacy of peripheral smear as a screening tool.

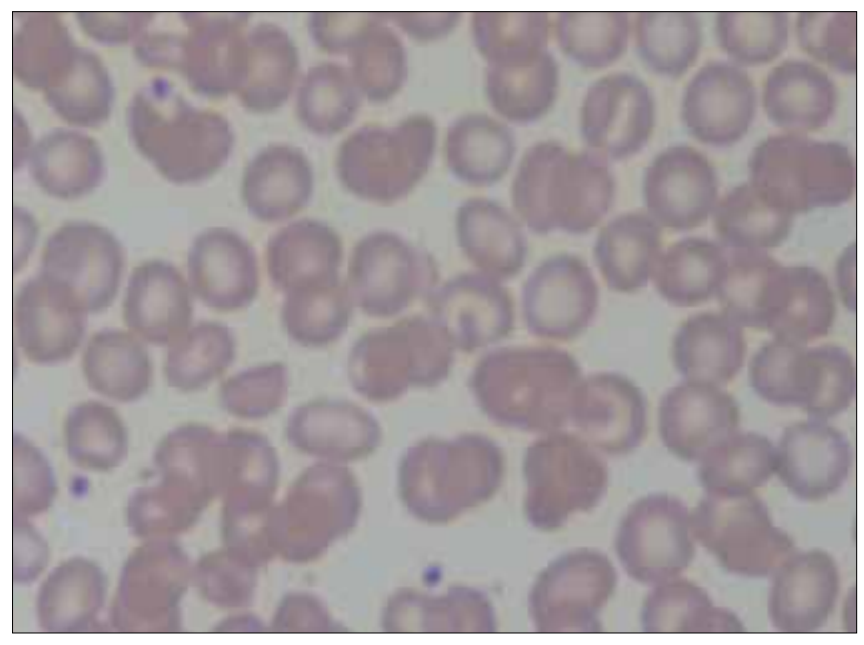

Figure 1: Peripheral smear showing Thalessemia trait (showing microcytic hypochromic RBCs) and presence of target cells (Leishman stain $\times 1000$ )

\section{RESULTS}

Of the 17623 smears examined, 60 smears were considered suspicious for T'T.

A similar number of $(n=60)$ Iron deficiency anemia patients with microcytic hypochromic blood picture, were considered as control group and, were evaluated.

The mean value of parameters $(1,2,3$ and 6$)$ is given as comparative statement in Table 1 . The alkaline hemoglobin electrophoresis done on the 60 suspected TT cases showed an elevated $\mathrm{Hb}$ A2 (mean $=7.5 \%$ ) indicating hemoglobinopathy. Of the 60 cases, 57 (95\%) cases showed electrophoresis results consistent with TT. Three cases showed a marked increase of the $\mathrm{Hb} \mathrm{A} 2 / \mathrm{C} / \mathrm{E}$ band (51.34, 52.19 and $35.82 \%)$ indicating hemoglobinopathy other than TT. These peripheral smears were re-evaluated and a diagnosis of $\mathrm{Hb}-\mathrm{E}$ was suggested, which required further confirmation by acid electrophoresis method. All cases of suspected iron deficiency were confirmed with either serum iron studies or bone marrow iron stores that was depleted. The morphological differences are summarized in Table 2. [Figures 1 and 2]. In the bone marrow, erythroid hyperplasia with normoblastic maturation was seen in both conditions, but the degree varied. Micronormoblastic maturation was also seen in $5 \%$ of the IDA cases.

\section{DISCUSSION}

Increasing social burden from thalassemic patients can be reduced only by awareness and use of effective tools to

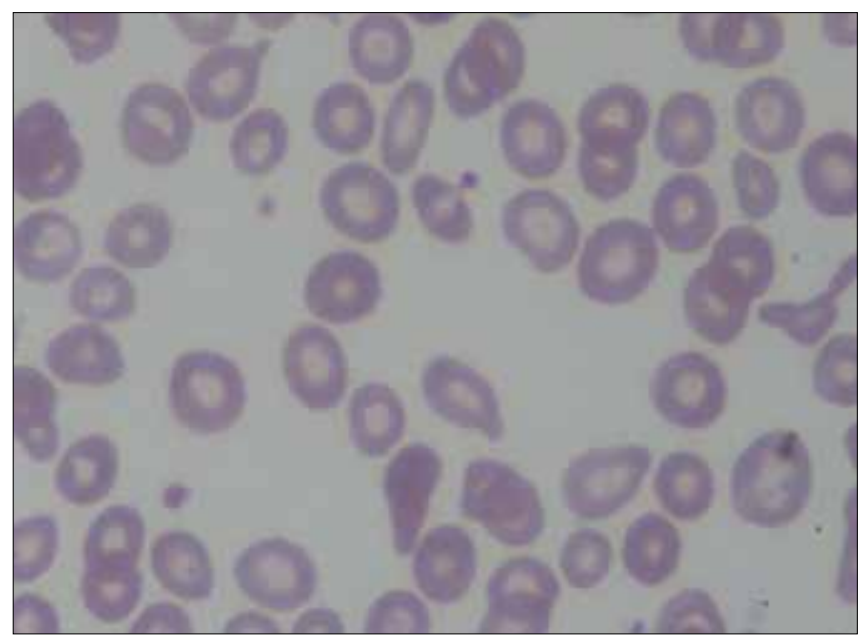

Figure 2: Peripheral smear showing iron deficiency anemia. Note the marked anisopoikilocytosis (Leishman stain $\times 1000$ )

Journal of Laboratory Physicians / Jan-Jun 2009 / Vol-1 / Issue-1 


\begin{tabular}{lcc}
\hline \multicolumn{3}{l}{$\begin{array}{l}\text { Table 1: Comparison of hematological } \\
\text { parameters in TT and IDA }\end{array}$} \\
\hline Parameter & Thalassemia trait & Iron deficiency \\
Hemoglobin (g/dl) & 11.39 & 5.44 \\
RBC Count (millions $\left./ \mathrm{mm}^{3}\right)$ & 5.74 & 3.19 \\
MCV (femtoliters) & 62.3 & 64.9 \\
RDW-CV\% & 18.78 & 22.58 \\
\hline
\end{tabular}

diagnose heterozygous carriers of the gene (T'T).

Microcytosis is a common red cell change seen in anemias of varying etiology. These include IDA, thalassemia, chronic disease and sideroblastic anemias. The microcytosis of heterozygous $\beta$-thalassemia needs to be distinguished from non-thalassemic microcytosis for its role in thalassemia control. ${ }^{[4]}$. Comparison of both groups showed significant differences between the two groups [Table 2].

Onofrio et al used $\mathrm{H}^{* 1}$ hematology analyzer, in which the percentile of microcytes and hypochromic cells were obtained. They found that there was an inverse relationship between the percentages of the microcytes (MCV $<60 \mathrm{fl}$ ) and the hypochromic cells (MCHC $280 \mathrm{~g} / \mathrm{L}$ ) in IDA and TT. Percentile of microcytes (mean 33.1\%) was higher than the hypochromic cells (mean 13.9\%) in TT. On the contrary, in IDA, the percentage of hypochromic cells (mean 34.6\%) was higher than the percentage of microcytes (mean $12.8 \%$ ) ${ }^{[5]}$ Bentley et al used Technicon $\mathrm{H}^{*} 1$ analyzer, which provides direct MCHC measurement (termed $\mathrm{CHCM}$, in addition to the conventional computed value (Hb/PCV). The mean values for both MCHC and CHCM were significantly lower in patients with IDA parallel to the above study. ${ }^{[6]}$

Kotwal et al, in their study found that the prevalence of IDA as a cause for microcytosis in India is high. ${ }^{\left[{ }^{4]}\right.}$ Hence, there are controversies on the choice of red cell indices to be used and assign cut-off values for distinction from TT. They overcame this difficulty by plotting Receiver Operating Characteristic (ROC) curves, and re-calculating the cutoff values for red cell indices in an Indian setting. The cut-off values defined by them were: MCV $<76 \mathrm{fL}$, $\mathrm{RBC}$ count $\geq 4.9 \times 10^{12} / \mathrm{L}$ and $\mathrm{RDW} \geq 18 \%$. Of these they observed RBC count to be the most efficient single test for distinguishing TT cases. ${ }^{[4]}$ In the present study, significant differences were found in the mean values of $\mathrm{Hb}$ percentage, $\mathrm{RBC}$ count and RDW with a positive predictive value of $95 \%$ [Table 1].

Various discriminative functions (DF) have been described using red cell indices and RBC count. Some of them are: 1. Mentzer ratio (MCV/RBC count); 2. England and Fraser

$\begin{aligned} & \text { Table 2: Morphological differences between TT } \\
& \text { and IDA }\end{aligned}$
\begin{tabular}{lcc} 
Parameter & TT & IDA \\
Microcytosis & ++ & + \\
Hypochromia & + & ++ \\
RBC count & Mild erythrocytosis & Anemia \\
Anisopoikilocytosis & - & + \\
\hline
\end{tabular}

index $(\mathrm{MCV}-(5 \times \mathrm{Hb})-8.4 ; 3 . \mathrm{MCH} / \mathrm{RBC}$ count and; 4. $(\mathrm{MCV}) 2 \times \mathrm{MCH}$.

Afroz et al used Mentzer ratio to discriminate between IDA and TT with a positive predictive value of $91 \%$. Mentzer ratio $>14 \%$ was marked as IDA. ${ }^{[7]}$ In the present study, the mean Mentzer ratio in T'T was 10.8 and in IDA was 19.7.

Various opinions have been suggested as to the role of DFs in the differential diagnosis of microcytosis. Eldibany et al analysed four groups of patients (normal, $\beta$-thalassemia, $\alpha$-thalassemia and IDA). They statistically analyzed RBC count, $\mathrm{Hb}, \mathrm{MCV}, \mathrm{MCH}$ and RDW by stepwise multivariate discriminant analysis and calculated by Fischer linear DF. They identified RBC count, MCV and RDW as the best set of indices to differentiate the diagnoses. The Fischer linear DF resulted in mean weighted sensitivity of $80.4 \% .{ }^{[8]}$ On the other hand, Bentley et al noted in $67 \%$ of the cases they studied that use of a DF did not resolve the diagnosis to the extent that $\mathrm{Hb}$ concentration and quantitation studies were no longer indicated. ${ }^{[6]}$ In the present study, mean $\mathrm{Hb}, \mathrm{RBC}$ count and RDW were found to be significantly different in the two groups evaluated.

\section{CONCLUSION}

Careful examination of the peripheral smears along with red cell indices are invaluable screening tools for TT (positive predictive value $=95 \%$ ). Creating awareness among the peripheral centers of thalassemia belts in using the above method will go a long way in reducing thalassemia major births.

\section{REFERENCES}

1. Lukens JN. The thalassemias and related disorders: Quantitative disorders of hemoglobin synthesis. In: Lee GR, Bithell TC, et al, editors. Wintrobe's Clinical hematology, $9^{\text {th }}$ ed. Philadelphia: Lea and Febiger; 1993. p. 1102-45.

2. Maheshwari M, Arora S, Kabra M,. Menon PS. Carrier screening and prenatal diagnosis of $\beta$ Thalassemia. Indian Pediatr 1999;36:1119-25.

3. Weatherall DJ. The thalassemia. In: Beutler E, Lichtman MA, et al, editors. Willams Hematology, $6^{\text {th }}$ ed. New York; McGraw Hill; 2001. p. 547-80.

4. Kotwal J, Saxena R, Choudhry VP, Dwivedi SN, Bhargava M. Erythrocyte indices for discriminating thalassaemic and non-thalassaemic microcytosis in Indians. Natl Med J India 1999;12:266-7. 
5. d'Onofrio G, Zini G, Ricerca BM, Mancini S, Mango G. Automated measurement of red blood cell microcytosis and hypochromia in iron deficiency and beta-thalassaemia trait. Arch Pathol Lab Med 1992;116:84-9.

6. Bentley SA, Ayuscue LH, Watson JM, Ross DW. The clinical utility of discrimant functions for the differential diagnosis of microcytic anemias. Blood 1989;15:575-82

7. Afroz M, Shamsi TS, Syed S. Predictive value of MCV/RBC count ratio to discriminate between iron deficiency anaemia and beta thalassaemia trait. J Pak Med Assoc 1998;48:18-9.

8. Eldibany MM Totonchi KF, Josepj AJ. Usefulness of certain red blood cell indices in diagnosing and differentiating thalassaemia trait from iron deficiency anemia. Am J Clin Pathol 1999;111:676-82.

Source of Support: Nil, Conflict of Interest: None declared.

Staying in touch with the journal

1) Table of Contents (TOC) email alert Receive an email alert containing the TOC when a new complete issue of the journal is made available online. To register for TOC alerts go to www.jponline.org/signup.asp.

\section{2) RSS feeds}

Really Simple Syndication (RSS) helps you to get alerts on new publication right on your desktop without going to the journal's website. You need a software (e.g. RSSReader, Feed Demon, FeedReader, My Yahoo!, NewsGator and NewzCrawler) to get advantage of this tool. RSS feeds can also be read through FireFox or Microsoft Outlook 2007. Once any of these small (and mostly free) software is installed, add www.jlponline.org/rssfeed.asp as one of the feeds. 